\title{
Fenomenología de la imaginación. Variaciones y perspectivas
}

\section{RiCARdo MENDOZa-CANALES}

Centro de Filosofia

Universidade de Lisboa

Faculdade de Letras

1600-214 Lisboa (Portugal)

rcanales@letras.ulisboa.pt

\begin{abstract}
Against a naive interpretation of imagination as the creation of a mental image that works as a representation of an external object or reference, the phenomenology of imagination emphasizes the description of the living experience of imagining and the form by which this experience is structured. This reveals the cognitive and aesthetic potential of the imaginative act and suggests that the modes can be seen as part of the way the imaginary unreal interacts and becomes part of our experience of the real world.
\end{abstract}

Keywords: Phenomenology, imagination, phantasy, unreal.
Resumen: Frente a una interpretación naíf que entiende por imaginación la creación de una imagen mental que opera como la representación de un objeto o referencia exterior, la fenomenología de la imaginación pone el énfasis en la descripción de la vivencia misma del imaginary en la forma como se estructura la experiencia. Con ello se revela el potencial cognitivo y estético del acto imaginativo, y permite entrever los modos como lo irreal imaginario interactúa y hace parte de nuestra experiencia del mundo real.

Palabras clave: Fenomenología, imaginación, fantasía, irreal. 
s un lugar bastante común decir que recordar es volver a vivir. Pero conviene quizás, para hacer justicia a la frase $-\mathrm{O}$ al menos ponerla en riguroso contexto-, traer a colación los primeros versos de las Coplas a la muerte de su padre de Jorge Manrique, cuando dice: "Recuerde el alma dormida / avive el seso e despierte / contemplando / cómo se passa la vida / cómo se viene la muerte / tan callando". Una voz imperativa se dirige a esa "alma dormida", exhortándola a "avivar el seso" (el sentido) para así, metafóricamente, despertar de su lecho mortuorio. La clave del pasaje reside en la primera palabra de ese primer verso: recuerde. La etimología de la palabra nos revela su belleza y plasticidad. "Recordar" es "re-cordar": del latín cor-, cordis, es decir, "corazón". El reiterativo "re-" subraya la intención de la acción: recordar es, literalmente, “(de)volver al corazón”, "volver a la vida".

$\mathrm{Al}$ igual que recordar, rememorar posee también una etimología interesante y pertinente. Viene del latín re-membrare, es decir, volver a juntar los miembros, los fragmentos. Y otra palabra afín, evocar, quiere decir, "volver a llamar". Recordar, rememorar y evocar nos invitan, pues, a perdernos en una red de sentidos (y aquí sentidos entendidos a la vez como orientaciones y como sensaciones) que se construye mediante una relación donde la emoción del corazón, la imagen reconstruida en y desde la memoria y el llamado de la voz se confunden y despliegan. El hombre que recuerda, rememora y/o evoca no hace sino revivir, reunir y/o convocar. Se conforma hoy a partir de los retazos del ayer.

Hay en el recuerdo una forma específica del acto de imaginar. $\mathrm{Y}$ el acto imaginativo, como apuntaba Sartre, "es un acto mágico". Lo imaginado muchas veces nos es dado como memoria de lo que fue experiencia. Y las memorias pueden ser de hechos, pero también compuesta de otros recuerdos o del recuerdo de expectativas pasadas, incluso aquellas que nunca llegaron a ser cumplidas. En nuestra vida cotidiana, pero también en cada acto cognitivo e intelectual, participan las imágenes y hacemos experiencia de ellas. No se

1. J. Manrique, Coplas a la muerte de su padre (Castalia, Madrid, 1989) 47.

2. J. P. SARTRE, Lo imaginario (Losada, Buenos Aires, 1964) 157. 
trata solo de figuraciones mentales, de ese tipo de representaciones visuales que "vemos" cuando cerramos los ojos. Imaginar no solo comporta un "ver", sino también todo un volcarse en lo visualizado. Ver, e imaginar, no son siempre formas análogas a la percepción que llamamos "visual". Junto a la materia propia de la imagen hay también estados de ánimo, recuerdos, afectos, afecciones de todo tipo y naturaleza. Como señala Martin Seel:

El recuerdo es un medio importante de la imaginación. Pero él también cuenta con la doble posibilidad de una referencia estética o no estética [...]. El acto de volver a sentir lo pretérito nunca está disociado de la representación de su perfil y de su perfume, de su sonido y de su sabor. El recuerdo de las emociones no es posible sin el recuerdo de la sensualidad que las enmarcaba ${ }^{3}$.

Un olor nos retrotrae hacia una casa antigua que alguna vez habitamos; un sabor (y aquí mencionar a Proust se vuelve inevitable) nos traslada a un momento específico de nuestra vida; en un sonido percibido resuenan todos los sonidos parecidos pacientemente recolectados cada verano. Nuestras fantasías (las más atroces y temibles, pero también aquellas amables y hasta inverosímiles) tienen como materia retales entramados por hilos tenues, delicados, transparentes, que dibujan formas y escenarios a los que somos devueltos unas veces, arrojados en otras, y hacemos experiencia presente de lo que es fácticamente ausente. Es en ese hiato, desde la sima que divide nuestro pasado y nuestro futuro (un instante sublime que a veces llamamos presente), donde emergen, desde insondables profundidades, los motivos y hábitos que dan forma a la vida consciente del sujeto ${ }^{4}$.

3. M. SeEL, Estética del aparecer (Katz, Madrid, 2010) 118.

4. "Una vinculación nueva de motivos habituales muy separados y sin relación mutua (en el subconsciente) inaugura nuevas ampliaciones, permite mirar hacia infinitudes, despierta formidables perspectivas nuevas sobre el conocimiento del mundo, evoca una abundancia infinita de conocimientos posibles. Todos los conocimientos previos (o masas enormes de ellos) son afectados, etc. A partir de ahí quisiera entender que se diga que tal pensamiento iluminador llega al corazón, nos mueve hacia las más hondas profundidades, pero proviene también de las más 
En un sentido general, ordinario, la imaginación y la fantasía suelen por lo general ser vinculados a actos mentales creativos, sean o no de tipo estético o artístico. En este sentido corriente, imaginar o fantasear algo es entendido como pensar en algo que se encuentra "fuera" de la realidad. Lo imaginado o fantaseado no existe más que en nuestra imaginación, ya que no hay objeto de la realidad extramental que sea adecuado a su representación mental. Bajo este criterio, un unicornio es un objeto imaginable o pertenece al mundo de la fantasía, pero no se le puede considerar "real". Y, sin embargo, mientras hacemos vivencia de la fantasía de un unicornio, éste "es". No se trata de juzgar como verdad o falsedad aquello que es objeto de la fantasía. Más interesante resulta tener en cuenta que, al margen de su determinación existencial, el solo hecho de hacer experiencia del unicornio ya conlleva un cierto grado de "creencia". Es decir: "creemos" en el unicornio que estamos imaginando.

La representación estética claramente opera bajo este principio. No solamente en cuanto acto creativo, sino también desde el punto de vista experiencial de quien se confronta con el objeto artístico ${ }^{5}$. Como señala Merleau-Ponty en un pasaje importante de su obra El ojo y el espíritu: "Esencia y existencia, imaginario y real, visible e invisible: la pintura embrolla todas nuestras categorías al desplegar su universo onírico de esencias carnales, de semejanzas eficaces, de significaciones mudas".

Se comienza entonces a vislumbrar la pregunta filosófica: ¿Qué clase de ser que no posee existencia tiene este objeto de la imaginación? Se pone en cuestión, pues, el estatuto ontológico de la ficción. Dada su naturaleza a medio camino entre hecho psíquico y pura irrealidad, entre el dato concreto de la vivencia psíquica y la mera posibilidad sin concreción de lo imaginado, la imaginación ofrece la

hondas profundidades”. E. HussERL, Carta de Husserl a Gerda Walther. Mediados de mayo, 1920 (borrador), "Acta Mexicana de Fenomenología” 2 (2017) 79.

5. Cf. E. Husserl, Carta a von Hofmannsthal, 12.01.1907, "Areté" XXIX/ 2 (2017) 428. Ver también mi artículo: R. MENDOZA-CANALES, Ver y no creer: imaginación, fantasía y conciencia de 'como si' en la fenomenología de Husserl, "Phainomenon" 27 (2018).

6. M. Merleu-Ponty, El ojo y el espiritu (Trotta, Madrid, 2013) 32. 
posibilidad de constituir representaciones de objetos inexistentes (el dios Júpiter, un centauro, la "visualización" de un dinosaurio a partir de algunos restos óseos), como también de "materializar" ideologías, "situar" utopías y facilitar su concreción afectiva conectándolas mediante la sensibilidad ${ }^{7}$. De otro lado, vivir en la imaginación (como, por ejemplo, haciendo vivencia de una ficción literaria) ofrece la posibilidad de suspender el estatuto que delimita, conforma y determina la realidad concreta, entendida como aquello que se experimenta como formando parte de una espacio-temporalidad concreta (bic et nunc). De este modo, como es posible advertir, la imaginación se constituye en una poderosa herramienta para desencajar determinaciones asentadas en "la realidad" y abrir así espacios de formulación de posibilidades alternativas, basadas en el juego libre entre las formas de sensibilidad (receptividad) y la conformación libre de conceptos del entendimiento (espontaneidad).

A diferencia de la percepción, que, por definición, se encuentra anclada en la realidad sensible, la imaginación abre la puerta a la libertad de la experiencia, vagando así en el interregno de la indeterminación y la posibilidad. Es por esto, y en virtud del componente empíricamente contrastable del primero, que a lo largo de la historia de la filosofía ha sido la percepción (en griego: aiesthesis) la que ha disfrutado de una incuestionada primacía ontológica sobre la imaginación (phantasia). Sin embargo, precisamente gracias a la independencia de los objetos ficticios, esto es, de los objetos de la fantasía, respecto de su anclaje en la realidad concreta (de allí que se les denomine también "irreales"), se erigen igualmente como formas legítimas de acceso al conocimiento. "La irrealización de lo particular", subraya Nathanson, inspirándose en Husserl, "es la afirmación de lo universal" ${ }^{8}$. La conciencia de posibilidad exige, pues, una conciencia libre, "y esta libertad se tiene que poder definir con un 'estar-en-el-mundo' que es a la vez constitución y anonadamiento de este mundo; la situación concreta en el mundo de la concien-

7. P. RiCOEUR, Ideology and Utopia as Cultural Imagination, "Philosophic Exchange" 7/1 (1976) 27.

8. M. Nathanson, The Erotic Bird: Phenomenology in Literature (Princeton University Press, Princeton, 1998) 34. 
cia tiene que servir en todo instante de singular motivación para la constitución de irreal" .

Es este componente de la experiencia imaginativa el que viene siendo puesto en relieve en la investigación más reciente sobre el tema. Se trata de desplazar la concepción de la imaginación y de la fantasía desde su sentido corriente - ligado a la imagen visual como objeto de representación - al abordaje de su rendimiento cognitivo y epistemológico, esto es, de las formas como la imaginación se manifiesta y, sobre todo, interviene en nuestra experiencia empírica y conocimiento del mundo ${ }^{10}$. Ejemplo de esto último lo constituyen las ensoñaciones, la toma de decisiones, una abstracción geométrica, la resolución de un problema matemático, los pronósticos, o la representación teatral, sea como el actor que encarna un personaje, sea como el espectador que suspende la realidad sensible para trasladarse al mundo de la ficción de la pieza. La imaginación y la fantasía intervienen también en la constitución de la intersubjetividad por medio de la empatía, el reconocimiento de la alteridad y la comunicación misma; todos ellos, dominios que hasta hace poco parecían reservados a la psicología, la ontología social o la semiótica, pero que vienen siendo revisitados últimamente desde la fenomenología con valiosos resultados ${ }^{11}$.

9. P. SARTRE, Lo imaginario cit., 229.

10. Desde diferentes aproximaciones teóricas y metodológicas, que abarcan perspectivas que van desde las ciencias cognitivas y la filosofía de la mente a la estética, la filosofía del lenguaje y la propia fenomenología, cabría mencionar, entre otros, los trabajos de D. LOHMAR, Phänomenologie der schwachen Phantasie (Springer, Dordrecht, 2008); K. L. Walton, Mimesis and Make-Believe (Harvard University Press, Cambridge, 1990); G. Currie, I. RavensCroft, Recreative minds: Imagination in philosophy and psychology (Oxford University Press, Oxford, 2002); R. Sorensen, Thought Experiments (Oxford University Press, Oxford, 1992); o A. KIND, P. KunG, Knowledge Through Imagination (Oxford University Press, 2016).

11. Ver los trabajos de D. Lohmar, Denken obne Sprache: Phänomenologie des nichtsprachlichen Denkens bei Mensch und Tier im Licht der Evolutionsforschung, Primatologie und Neurologie (Springer, Dordrecht, 2016); M. RaTCLIFFE, Experiences of Depression: A Study in Phenomenology (Oxford University Press Oxford, 2015); T. BREYER, Verkörperte Intersubjektivität und Empathie (Klostermann, Frankfurt am Main, 2015); o B. WALDENFEls, Grundmotive einer Phänomenologie des Fremden (Suhrkamp, Frankfurt am Main, 2006). 
A pesar de esta aparente novedad, el tratamiento filosófico sobre la imaginación y la fantasía poseen una larga tradición en el pensamiento occidental. Por ejemplo, ya Platón reconocía un tipo particular de conocimiento de las ideas bajo la forma de la reminiscencia $^{12}$. Y Aristóteles consideraba a la imaginación (phantasia) como un mediador entre la percepción y el intelecto ${ }^{13}$. El rendimiento cognitivo de la imaginación como contrapolo a la percepción ha sido un problema que ha recorrido la historia de la filosofía, ocupando el interés de Plotino a Agustín; de Tomás de Aquino a Duns Scoto y Francisco Suárez; de Descartes, Spinoza y Leibniz, a Locke, Berkeley y Hume. De Kant y Hegel a Schopenhauer y Nietzsche. En el siglo XX, la investigación filosófica en torno a la imaginación (en la así llamada tradición "continental") ha sido tradicionalmente abordada desde la perspectiva de la estética, de la teoría de las artes, de los estudios sobre comunicación y Media Studies, de la teoría literaria o, por último, desde el psicoanálisis. No obstante, todas estas propuestas comparten un mismo punto de partida, que puede ser doble: o bien la imagen como objeto de representación, o bien la representación como conformadora de imágenes. En uno u otro caso, se trata de evaluar el estatuto objetual de la imagen entendiéndola como un objeto ya constituido o un símbolo que cabe interpretar. Por su parte, la tradición analítica ha ofrecido desde la lógica y la filosofía del lenguaje textos decisivos para el tratamiento de la ontología de lo imaginario y lo posible; asimismo, y más recientemente, también hay un interés creciente en lo ficcional y la determinación de la realidad y la verdad ${ }^{14}$.

12. Platón, Menón, Diálogos II: Gorgias, Menéxeno, Eutidemo, Menón, Crátilo (Gredos, Madrid, 1992), en especial, 301-313 (81a-86c).

13. Aristóteles, Acerca del alma (Gredos, Madrid, 1988), en especial, 222-229 (427a16-429a10).

14. Ver, por ejemplo, los trabajos de N. Goodman, Ways of Worldmaking (Hackett, Indianápolis, 1978); S. KRIPKE, Name and Necessity (Harvard University Press, Cambridge, 1980); J. McDowell, Mind and World (Harvard University Press, Cambridge, 1996); o G. CURRY, The Nature of Fiction (Harvard University Press, Cambridge, 1990); los cuales manifiestan varios puntos coincidentes con posiciones defendidas desde la fenomenología. 
La corriente fenomenológica, entendida como las líneas de pensamiento filosófico que se engarzan y se proyectan desde la obra de su fundador, Edmund Husserl, ha tratado extensamente la relación entre experiencia, percepción e imaginación. Además de Husserl, autores pertenecientes a la tradición fenomenológica como Heidegger, Sartre o Merleau-Ponty se han ocupado de esta problemática y sus obras han inspirado, a su vez, a otros autores que trabajan en temas vinculados a la teoría de la imagen o cuestiones de estética.

Que el monográfico esté dedicado a una fenomenología de la imaginación comporta que la imaginación, entendida como acto mental, será el eje temático del mismo. Eso quiere decir que el tratamiento recaerá en relación constituyente entre el mundo (y la experiencia del mundo) y la imaginación; o dicho en otros términos: de cómo lo "irreal" imaginario interviene en la conformación de la realidad perceptual. Por otra parte, plantear la cuestión acerca del estatuto de la imaginación desde una perspectiva fenomenológica permite situarla en la confluencia de dos ámbitos de análisis: por un lado, en el análisis de las condiciones de posibilidad y de los modos de experimentación de lo imaginario, lo que permite conectar con lecturas de filosofía práctica (estética, ética y filosofía política). Por otro lado, permite enfocar el análisis desde el estatuto cognitivo de la imaginación, es decir, acerca del posible valor epistémico de las representaciones imaginativas con respecto al conocimiento de la realidad y de la posibilidad (como en la ficción); lo cual se inscribe claramente en una vertiente de la filosofía estrictamente teorética.

El objetivo de este volumen monográfico es reunir contribuciones que, entroncadas en la investigación fenomenológica más actual, aporten aproximaciones sobre la imaginación y establezcan líneas transversales de investigación desde el pensamiento fenomenológico. Asimismo, los artículos que componen el monográfico mantienen un equilibrio entre dos perspectivas complementarias: una perspectiva histórica, en la que los autores de las contribuciones aportarán lecturas novedosas sobre los filósofos estudiados; y una perspectiva sistemática, en la que se abordan problemáticas actuales.

Los artículos reunidos en este número de Anuario Filosófico confrontan las diferentes facetas del fenómeno y la experiencia imagina- 
tiva. Es importante destacar en este punto la actualidad de la fenomenología husserliana, pues funciona como un hilo conductor de los artículos aquí reunidos. La obra de Husserl, ya lejos de su encuadramiento reduccionista en la mal llamada "filosofía de la conciencia", brinda, partiendo de su carácter descriptivo, como también con su búsqueda de una filosofía "como ciencia rigurosa", un fundamento cognitivo que sirva de soporte teórico respecto de la experiencia de la imagen y de la imaginación. Los aportes husserlianos, tanto terminológicos como descriptivos, resultan iluminadores con respecto al problema del estatuto de la imagen, de la fantasía, de la ficción y de la propia experiencia estética. A pesar de que sus manuscritos inéditos relativos a la fantasía y la conciencia de imagen aparecieron publicados en 1980 en la colección Husserliana-Gesammelte Werke, solo en las últimas dos décadas han comenzado a dar frutos y hoy en día atraen la atención no solo de los especialistas en su obra, sino también en el ámbito de la investigación interdisciplinaria gracias a sus múltiples aplicaciones.

A continuación, quisiera ofrecer un breve panorama de los contenidos recogidos en este número especial de Anuario Filosófico.

El primer artículo, firmado por Emmanuel Alloa, propone una reinterpretación de la phantasia en Aristóteles. Según una interpretación hegemónica, ésta se trataría de una facultad autónoma del alma por la cual somos capaces de representar imágenes, de modo que Aristóteles habría sido el primero en formular la phantasia como aquella facultad que salva la distinción entre percepción y entendimiento. Alloa desafía esta interpretación al considerar que se encuentra influenciada, de manera retrospectiva, por la doctrina de las facultades de Kant. A partir de una lectura atenta de De anima, Alloa concluye que para Aristóteles la phantasia es ante todo un evento "medial" y debe ser entendida como la dimensión visualizante que se extiende a través de las otras facultades, esto es, como la fuente por antonomasia de toda fenomenalidad.

El segundo artículo, a cargo de César Moreno, explora el universo de los objetos que él denomina impelentes, esto es, que reclaman al sujeto de experiencia —y, más aún, le motivan- formas posibles de realidad que no se reducen únicamente a la realidad efec- 
tiva, sino que co-habitan, a pesar de su irrealidad, en el seno de lo real. De este modo, como señala Moreno, la imaginación permite abrir la posibilidad de incorporar en el horizonte intencional sentidos del objeto que se vuelven irreductibles a una mera condición de determinación, y que es precisamente por su carácter imaginario (no real: irreal) que trastocan el fondo de determinación que habilita lo que comúnmente denominamos "realidad". La aproximación de Moreno conjuga eficazmente la fenomenología trascendental de corte husserliano con su variante hermenéutica, inaugurada por Heidegger, y se apoya en una lectura operativa de Sloterdijk y Ramón Gómez de la Serna.

A continuación, Javier Carreño propone una puesta en valor de Mikel Drufenne, cuya obra, a pesar de su relevancia en el medio filosófico francés en las décadas de 1950 y 1960, fue inexplicablemente perdiendo visibilidad y protagonismo. Carreño confronta algunas ideas clave del clásico Fenomenología de la experiencia estética (1953, 2 vols.) de Dufrenne con los manuscritos inéditos de Husserl sobre la fantasía, los cuales aparecieron publicados casi treinta años después de la obra del primero. Para Carreño, Dufrenne, únicamente partiendo de los aportes de Sartre y Merleu-Ponty, alcanza conclusiones semejantes a las de Husserl, las cuales obviamente ignoraba. Carreño no solo subraya las coincidencias entre ambos autores, sino, sobre todo, rescata la concepción temporal inherente a las imágenes que ambos autores, aunque con ligeras discrepancias, confieren a la propia experiencia pictórica.

Seguidamente, Regina-Nino Mion efectúa una lectura a la vez analítica y descriptiva de la teoría husserliana de la imaginación física. Para la autora, la imaginación física constituye una forma específica de imaginación, distinta, por tanto, a otras formas de intuición como son la fantasía y la percepción. Precisamente, a partir de esta idea, Mion reconstruye la teoría husserliana de la conciencia de imagen, subrayando y discerniendo los componentes que intervienen en las intuiciones de fantasía: los contenidos más elementales de toda representación serán los phantasmas, y constituyen contenidos aprehensionales presentificados por oposición a los contenidos de la intuición perceptual, las sensaciones, que son dados "en presencia". 
De este modo, como concluye la autora, contemplar una imagen física conlleva un tipo de conciencia distinto de aquel de la imaginación productiva, que carece de anclaje en cualquier soporte material y, por ello, flota libremente en la fantasía.

Las conclusiones del artículo anterior sirven de prolegómeno para el último artículo, firmado por Pol Vandevelde. El autor se cuestiona el rol que cumple la imaginación en un tipo de fenómeno particular: la narración de hechos reales o acontecimientos. Apoyándose en la teoría del relato de Paul Ricoeur, Vandevelde parte del problema de cómo un relato puede alcanzar a presentar hechos de modo fidedigno y, para ofrecer una posible respuesta, recurre a la noción de "phantasma" de Husserl. Su tesis consiste, luego, en que lo que nos permite visualizar y experimentar la historia contada en un relato es un phantasma análogo a las sensaciones de las percepciones captadas por los testigos presenciales de tales hechos. Este componente imaginativo de la narración nos permite, bajo la forma de lo que Husserl llamó "como si”, hacer experiencia y extraer conocimiento de acontecimientos que no hemos vivido en primera persona.

Para finalizar, solo me queda agradecer a los miembros del equipo editorial de Anuario Filosófico por haber creído en su momento en este proyecto y por su constante apoyo a lo largo de los últimos meses hasta su concreción. De igual modo, va mi reconocimiento a los revisores anónimos que tan amablemente aceptaron colaborar con este volumen y cuyas observaciones, críticas, anotaciones y sugerencias, sin lugar a dudas, han contribuido a elevar aún más la calidad de las contribuciones que hoy ponemos en las manos de los lectores. 

ESTUDIOS 
